Prepared for the U.S. Department of Energy

under Contract DE-AC05-76RL01830

\title{
Joint IAEA/NNSA International Workshop Nuclear Forensics Methodologies for Practitioners 2013 Scenario Based Exercise - Version 4.0 Instructor's Manual
}

$\begin{array}{ll}\text { JM Schwantes } & \text { PL Gassman } \\ \text { M Douglas } & \text { DE Meier } \\ \text { SM Morley } & \text { RM Pierson } \\ \text { DM Hill } & \text { MS Wallenius } \\ \text { P Thompson } & \text { NE Marks } \\ \text { PA Santi } & \end{array}$

October 2013

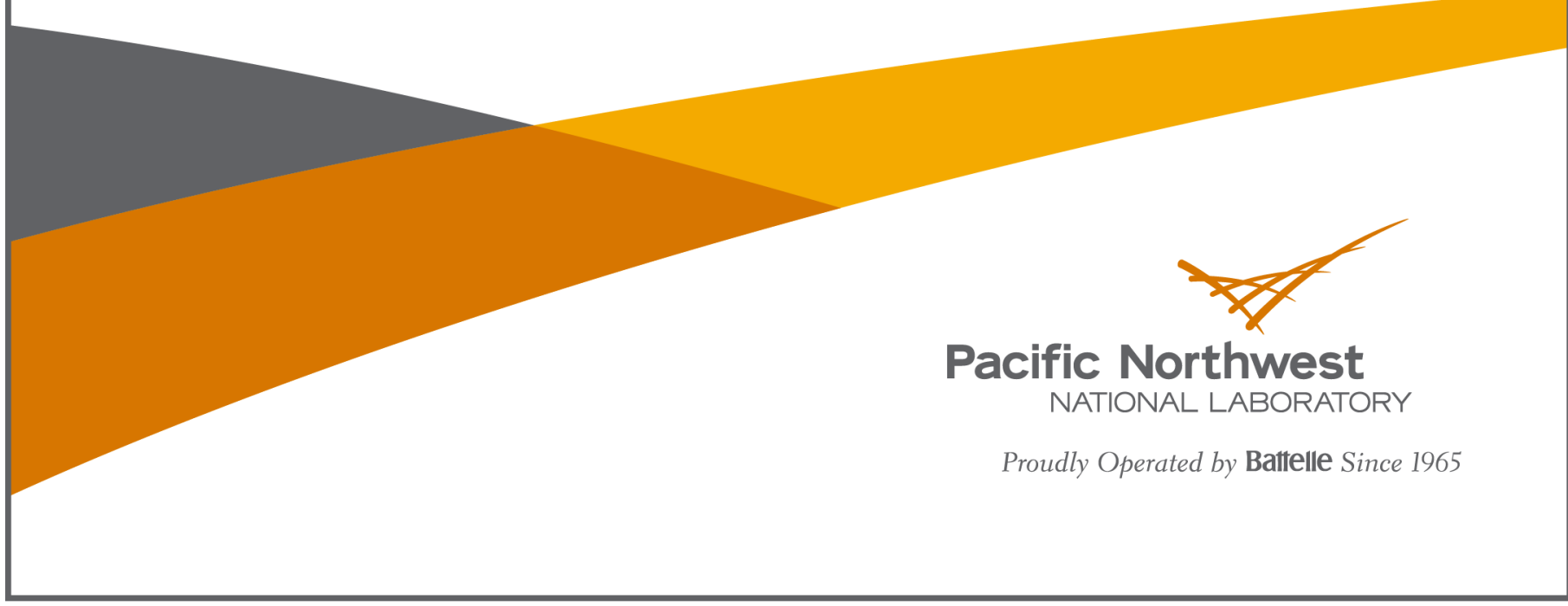




\title{
DISCLAIMER
}

This report was prepared as an account of work sponsored by an agency of the United States Government. Neither the United States Government nor any agency thereof, nor Battelle Memorial Institute, nor any of their employees, makes any warranty, express or implied, or assumes any legal liability or responsibility for the accuracy, completeness, or usefulness of any information, apparatus, product, or process disclosed, or represents that its use would not infringe privately owned rights. Reference herein to any specific commercial product, process, or service by trade name, trademark, manufacturer, or otherwise does not necessarily constitute or imply its endorsement, recommendation, or favoring by the United States Government or any agency thereof, or Battelle Memorial Institute. The views and opinions of authors expressed herein do not necessarily state or reflect those of the United States Government or any agency thereof.

\author{
PACIFIC NORTHWEST NATIONAL LABORATORY \\ operated by \\ BATTELLE \\ for the \\ UNITED STATES DEPARTMENT OF ENERGY \\ under Contract DE-AC05-76RL01830
}

Printed in the United States of America
Available to DOE and DOE contractors from the Office of Scientific and Technical Information,
P.O. Box 62, Oak Ridge, TN 37831-0062;
ph: (865) 576-8401
fax: $(865)$ 576-5728
email: reports@adonis.osti.gov

Available to the public from the National Technical Information Service

5301 Shawnee Rd., Alexandria, VA 22312

ph: (800) 553-NTIS (6847)

email: orders@ntis.gov <http://www.ntis.gov/about/form.aspx>

Online ordering: http://www.ntis.gov 


\title{
Joint IAEA/NNSA International Workshop Nuclear Forensics Methodologies for Practitioners 2013 Scenario Based Exercise - Version 4.0 Instructor's Manual
}

\author{
JM Schwantes \\ PL Gassman \\ M Douglas \\ DE Meier \\ SM Morley \\ DM Hill \\ P Thompson \\ RM Pierson \\ MS Wallenius \\ NE Marks \\ PA Santi
}

October 2013

Prepared for

the U.S. Department of Energy

under Contract DE-AC05-76RL01830

Pacific Northwest National Laboratory

Richland, Washington 99352 



\title{
Joint IAEA / NNSA International Workshop Nuclear Forensics Methodologies for Practitioners 2013 Scenario Based Exercise - Version 4.0 Instructor's Manual 28 October 2013
}

\author{
Jon M. Schwantes ${ }^{1}$, Paul Gassman ${ }^{1}$, Matthew Douglas ${ }^{1}$, Shannon Morley ${ }^{1}$, Richard Pierson ${ }^{1}$, David \\ Meier $^{1}$, Naomi Marks ${ }^{2}$, Peter Santi ${ }^{3}$, David Hill ${ }^{4}$, Maria Wallenius ${ }^{5}$ and Paul Thompson ${ }^{6}$ \\ ${ }^{1}$ Pacific Northwest National Laboratory, Richland, WA, USA \\ ${ }^{2}$ Lawrence Livermore National Laboratory, Livermore, CA, USA \\ ${ }^{3}$ Los Alamos National Laboratory, Los Alamos, NM, USA \\ ${ }^{4}$ Australian Nuclear Science and Technology Organization, New South Wales, Australia \\ ${ }^{5}$ European Commission, Institute for Transuranium Elements, Karlsruhe, Germany \\ ${ }^{6}$ AWE, Aldermasten, UK
}

\begin{abstract}
SBE 1: Radiation Portal Monitoring at Reimerland \& Radiological Crime Scene Management You are serving as a Reimerland border guard at Checkpoint (CP) 2 (see Appendix A for a country map and Dossier of Reimerland and the surrounding region). Your morning starts off with an intelligence briefing that indicates guards at the Country's northern Checkpoints should be especially vigilant and on the lookout for any suspicious activities. You are reminded that any vehicle alarming portal monitors will require a secondary screening. If at any time during secondary screenings anything seems out of the ordinary (e.g., shipping manifests do not match cargo, inconsistencies arise during questioning of the driver), you are to immediately contact agents from Reimerland's National Law Enforcement Agency (NLEA) to investigate further. If a vehicle sets off both gamma and neutron alarms, contact NLEA directly once these alarms are confirmed during secondary screening. [Participants will serve as border guards for Reimerland. They will be given brief instruction on the operation of hand-held RadioIsotope DetectorS (RIDS) and be provided an intelligence briefing that tells them to be on the lookout for suspicious activity at their post. Their instruction will include directing suspicious vehicles to a location for secondary screening. If, after secondary screening, suspicions of a criminal act involving nuclear and or radioactive materials remain, participants have been instructed to request assistance from the NLEA, who will then setup and manage a radiological crime scene. Participants will watch a demonstration of two vehicles containing radioactive materials driving through and setting off a portal monitor. The first vehicle, a semi-tractor trailer, sets off only a gamma alarm. After the driver provides a shipping manifest of fertilizer, participants, posing as border guards, are expected to waive this vehicle through inspection. The second vehicle, an SUV, set off both gamma and neutron alarms. The alarming of the neutron monitor should prompt participants to set up a secondary inspection of the vehicle immediately. The driver of the vehicle indicates he is in legal possession of an industrial instrument containing an old ${ }^{133} \mathrm{Ba}$ source that has decayed to a level no longer requiring official paperwork according to the IAEA and internationally accepted transportation regulations. Authorities have verified that the industrial source does fit the description of one that is sold commercially. However, upon setting up a secondary screening, participants will use hand-held detectors to locate several other radioactive sources emanating from a black duffle bag in the rear of the vehicle (Figure 1). Hand held detectors detect the presence of ${ }^{133} \mathrm{Ba}$, and $\mathrm{Pu}$. Upon questioning, the driver only commits to having the ${ }^{133} \mathrm{Ba}$ industrial source and cannot account for the detection of neutrons within his vehicle. Since neutron alarms also sounded, participants should indicate that a neutron alarm would be inconsistent with a ${ }^{133} \mathrm{Ba}$ source alone and should therefore conclude further investigation is warranted. This will prompt participants to call in a response team from the NLEA to set up a radiological crime scene around the vehicle in question. The response team is able to shoot a 3-D X-ray radiograph of the duffle bag without moving it to ensure it is rendered safe and moveable without disturbing the contents in
\end{abstract}


the field (Figure 2). At this point, the duffle bag is entered into inventory as evidence and a chain of custody form is initiated. Swipes are taken from the outer bag to confirm there is no dispersible contamination. The bag and its contents are considered valuable for the investigation by the lead investigator. He determines the duffle bag is safe to transport to RRL for evidence inventory and analysis. The duffle bag and its contents are packaged and sent off to the RRL.]

\section{SBE 2: Receipt of Evidence, Inventory, and Basic Physical Measurements}

Agent Schwantes from Reimerland's National Law Enforcement Agency (NLEA) seeks assistance by your laboratory (Reimerland Radioanalytical Laboratory - RRL) for the processing and analysis of nuclear forensic and potentially radioactively contaminated evidence. A black duffle bag containing radioactive materials was seized by authorities after the search of a late model Durango-Sport Utility Vehicle that set off radiation portal alarms on October 29, 2013, at approximately 8:23 am at border CP 2. The driver of the vehicle, Amennl Yami (a Reimerland national that has been living in Chicoland for the past 16 years), indicated he was on his way to a construction site located in Reimerland with an industrial instrument containing a radioactive source of ${ }^{133} \mathrm{Ba}$. He provided documentation to Customs representatives claiming the possession of this amount of activity/quantity of a radioactive substance is exempt from IAEA transportation regulations.

The duffle bag of evidence is received at RRL. The lead investigator indicates the outer portion of the duffle bag has been surveyed and has no detectable dispersible contamination, however, contents within the bag have not yet been surveyed. He instructs the lab staff to inventory the contents within the bag and survey each item for dispersible contamination, while maintaining or initiating chain-of-custody records for each of the pieces of evidence. Lab staff are to segregate, if possible, evidence that do not contain or are not contaminated with nuclear or radioactive materials. Evidence not contaminated with or containing nuclear or radioactive materials should be sent to the NLEA's traditional forensics laboratory. Participants will prepare individual items for gamma spectrometry screening by placing items in secondary containment. After gamma screening and segregating evidence, basic physical measurements (e.g., pictures, mass, dimensions, density) should be performed at RRL on any evidence found to contain or be contaminated with nuclear or radioactive materials.

[The duffle bag will be unpacked initially within a glove bag by participants to ensure contamination control and that evidence is safe to handle and free of dispersible radiological contamination. Items will be swiped and inventoried. All major pieces of evidence will be scanned initially by a low-background $\mathrm{NaI}(\mathrm{Tl})$ gamma spectrometer to determine the presence of radioactive materials (students will place items in secondary containment for screening, but no actual screening will be done. Instead, instructors will then identify which items are "radioactive" and which are not). Based upon those results, items will be segregated and either sent off to the NLEA forensics lab or processed further at RRL.

[Evidence contained within the duffle bag includes:

1. Plastic bag (with apparent fingerprint on the bag).

\subsection{Lab coat \\ 1.2. Lab gloves}

2. Manila envelope

\subsection{Several documents}

3. Small zip-lock bag

3.1. Plastic bottle

\subsubsection{Dark grey powder}

3.2. Plant seed

3.3. One hand-written document contaminated with radioactivity

4. Glass vial

4.1. Yellow liquid 
Gamma screening indicates items 1 and 2 are free of radioactive contamination and should be sent to the traditional forensics laboratory for further processing. However, staff at RRL should conduct basic physical measurements on the remaining pieces of evidence. This should include taking photos of 3.3 and sending those photos off for translation and handwriting analysis. Pictures and masses of 3.1, 3.2, and 4. Microscopy pictures of 3.1.1. and 3.2. Density measurements of 3.1.1. and 4.1. NLEA will translate the handwritten note based upon photos your lab provides. The note will be a description of the processing plan illustrated in Figure 3. Handwriting analysis will match the handwriting from the suspect to the handwriting of this note. The density of 3.1.1. will be consistent with $\mathrm{PuO}_{2}$. The mass of 3.1.1 will be greater than $500 \mathrm{mg}$. Appendix B contains a summary of the main results expected from SBE 2.]

\section{SBE 3: Development of an Analytical Plan}

Authorities would like for you to help them determine if a law has been broken. In Reimerland it is unlawful to have in your possession greater than $500 \mathrm{mg}$ of SNM (U of any ${ }^{235} \mathrm{U}$ enrichment above that of natural abundance, or $\mathrm{Pu}$ ) without proper documentation.

They have asked you to develop an analytical plan to analyze evidence pieces 3.1.1, 3.3. and 4.1 using capabilities you have in house (see Table A-1).

[Participants should propose the use of gamma and alpha spectrometry and the results of the basic physical measurements to confirm the identity of evidence piece 4.1. as a ${ }^{133} B a$-containing liquid and evidence piece 3.1.1. containing greater than $500 \mathrm{mg}$ of Pu. Alpha spectrometry should also be proposed for analyzing the contamination on evidence piece 3.3. The amount of contamination is too small for accurate gamma spectrometry. Additionally, alpha spectrometry will be helpful for the purpose of better quantifying minor actinide isotopes if gamma spectrometry confirms the presence of an actinide.]

\section{SBE 4: Gamma Spectroscopy}

The Lead Investigator has approved your analytical plan to use gamma spectrometry to confirm the presence of SNM within several of the evidence pieces recovered. RRL staff scientists are approved to conduct gamma ray spectrometry on evidence pieces 3.1.1 and 4.1. The small amount of contamination found on evidence piece 3.3 is not sufficient to justify approval of gamma spectrometry on this item. [Results of analyses indicate evidence item 3.1. contains Pu. In addition, evidence item 4.1. is found to contain the isotope ${ }^{133} \mathrm{Ba}$. From basic physical measurements previously conducted on this material, the mass of this material would require proper documentation to possess. Since no documentation covering this material could be provided by the driver, this event should become a criminal investigation and the driver should be brought up on charges of possessing SNM without a permit. Gamma spectrometry should identify the Pu as relatively low burn-up material, consistent with weapons grade Pu. Significant quantities of ${ }^{241} \mathrm{Am}$ will also be discovered in the gamma spectrum, suggesting that this material had aged since its last chemical separation. The ${ }^{133} \mathrm{Ba}$ detected in evidence piece 4.1 was not in a form or mass consistent with industrial applications. Participants may suggest that its presence may have been used to mask the gamma lines and identity of $P u$. Appendix $C$ contains a summary of the main results expected from SBE 4.]

\section{SBE 5: Alpha Spectroscopy}

The Lead Investigator has approved your analytical plan to use alpha spectrometry to confirm the presence of SNM within several of the evidence pieces recovered. RRL staff are approved to conduct alpha spectrometry on evidence pieces 3.3 and 4.1 .

[Alpha spectrometry of 3.3 will reveal the presence of a small amount of Pu, with a ${ }^{238} \mathrm{Pu}{ }^{239,240} \mathrm{Pu}$ ratio consistent with the Pu in item 3.1.1. The isotope ${ }^{241}$ Am should be measureable and quantified by participants. Appendix D contains a summary of the main results expected from SBE 5.]

\section{SBE 6: Database Query of State Holdings}

Lead investigator has requested your assistance in helping them determine if evidence piece 3.1.1. could have originated from within the State of Reimerland. Reimerland authorities have developed and maintained a database of State holdings of nuclear and radioactive materials, known as the National Nuclear Database (NND). Specifically, the database includes a summary of the State's holdings of nuclear materials, including uranium ore concentrates (from its extensive mining operations), fresh and 
spent nuclear fuel related to its power and research reactors. Also included in the NND are IAEA Category I and II radioactive sealed sources that include irradiators, teletherapy sources, industrial radiography sources, and neutron and gamma well loggers. They request that you assist them in querying this database in order to determine if any of these holdings are consistent with item 3.1.1. Based upon the analytical information you have currently, determine if evidence piece 3.1.1. matches any of the State's holdings by querying the database.

[Participants should be able to reduce the number of possible matches by excluding all sources that do not contain Pu. Gamma spectrometry should be able to further eliminate the possibility that this Pu came from spent nuclear fuel (SNF) caches from the OPAL research reactor based upon (1) significant differences between the ${ }^{242} P u$ abundance in the SNF and evidence piece 3.1.1. and (2) the significant differences between the ages of the two materials. Plutonium-Beryllium (PuBe) sources $Y-1$ through Y-5, manufactured in Yosemland, are also inconsistent (within 2- $\sigma$ uncertainty) with the unknown material based upon a comparison of ${ }^{239} \mathrm{Pu}$ and ${ }^{240} \mathrm{Pu}$ abundances.

Alpha spectrometry results provide an accurate measure of the age of the unknown material, which is calculated to be $16.3 \pm 1.14$ years old at $2-\sigma$. This age determination further eliminates the possibility that this material likely came from either of the PuBe sources manufactured in Chicoland. Appendix E summarizes expected results for SBE 6.]

\section{SBE 7: Revised Analytical Plan \& Advanced Interpretation I}

Authorities have realized that more precise and accurate measurements of evidence piece 3.1.1. are needed to further investigate the origin of this material, based upon your efforts to match the unknown materials up with the State's inventory summarized in the NND. The Lead investigator has requested that you propose a revised analytical plan that will task more advanced capabilities maintained and operated at the National Environmental Radiation Laboratory (NERL) at the Reimerland Institute of Technology. You are familiar with these capabilities because you have collaborated with scientists from this institution many times in the past and RRL has set up a memorandum of understanding between them and NERL for providing analytical assistance in forensic investigations. A list of the Institute's radioanalytical capabilities is provided in Table A-1.

[Participants should propose the use of both ICP-MS and possibly ICP-OES. After discussing the analytical plans, data inject (DI) \#1 is provided to participants.

DI\#1: ICP-MS analytical results on evidence piece 3.1.1. provided by NERL.

$\begin{array}{lllllllllll}\text { Evidence } & { }^{239} \mathrm{Pu} & 1-\sigma & { }^{240} \mathrm{Pu} & 1-\sigma & { }^{241} \mathrm{Pu} & 1-\sigma & { }^{242} \mathrm{Pu} & 1-\sigma & { }^{241} \mathrm{Am} & 1-\sigma \\ \text { Piece } & (\%) & & (\%) & & (\%) & & (\%) & & (\%) & \\ \text { 3.1.1. } & 97.83 & 0.36 & 1.91 & 0.102 & 0.0099 & 0.00042 & 0.0027 & 0.00035 & 0.0113 & 0.000297\end{array}$

Comparing this data with the database holdings will allow participants to further limit the list of potential materials matching the unknown. Based upon a more refined Pu/Am chronometer age estimated from ICP-MS data the PuBe source Y-6 (manufactured in Yosemland) may be excluded as a potential source of the evidence piece 3.1.1. Additionally, evidence piece 3.1.1. is inconsistent with the PuBe source Y-8 based upon the ${ }^{242} P$ abundance. A summary of expected outcomes from SBE7 is provided in Appendix F.]

SBE 8: Revised Analytical Plan \& Advanced Interpretation II

LE asks for your continued support to compare advanced analyses of the materials in question in order to confirm or deny links between the current investigation and the two remaining items in Reimerland inventory. You are your Country's Point of Contact to the Nuclear Forensics International Technical Working Group (ITWG). Through this organization, assistance is available from countries that have advanced nuclear forensics analytical capabilities. The Lead investigator has requested that you propose a 
second revised analytical plan that would utilize advanced analytical capabilities represented by your colleagues within the ITWG. A list of advanced analytical capabilities available through collaboration with ITWG colleagues is listed in Table 2.

Table 2. List of possible analyses available through ITWG collaborators.

Atomic Absorption

Spectrophotometer (AAS)

Inductively Coupled Plasma -

Mass Spectrometer (ICP-MS)

Scanning Electron Microscopy
Inductively Coupled Plasma -

Optical Emission

Spectrophotometer (ICP-OES)

$\mathrm{X}$-ray Diffraction (XRD)

Transmission Electron

Microscopy
Multi-Collector (MC) ICP-MS

CHN analyzer

[ With RRLs assistance, the lead investigator has been able to narrow down the potential links between this most recent seizure and State holdings within the NND to just two possibilities, a single PuBe source (Y-5) manufactured 16.8 years earlier in Yosemland and a prototype PuBe source (R-1) manufactured at the research reactor in Reimerland 15.6 years ago. List will contain MC-ICP-MS and XRD. The use of these analyses on item 3.1.1. and the two remaining materials in Reimerland holdings should be proposed in the revised analytical plan. Once analytical plans are received, results of these analyses are provided back to the participants as DI\#2.

DI\#2: MC-ICP-MS analytical results on evidence piece 3.1.1. provided by NERL.

\begin{tabular}{|c|c|c|c|c|c|c|c|c|c|c|}
\hline $\begin{array}{l}\text { Evidence } \\
\text { Piece }\end{array}$ & $\begin{array}{l}{ }^{239} \mathrm{Pu} \\
(\%)\end{array}$ & $1-\square$ & $\begin{array}{l}{ }_{(\%)}{ }^{240} \mathrm{Pu} \\
(\%)\end{array}$ & 1- $\square$ & ${ }_{(\%)}^{{ }^{241} \mathrm{Pu}}$ & 1- $\square$ & ${ }_{(\%)}^{{ }^{242} \mathrm{Pu}}$ & 1- $\square$ & $\begin{array}{l}{ }_{(\%)}^{241} \mathrm{Am} \\
(\%)\end{array}$ & 1- $\square$ \\
\hline 100 & 97.71 & 0.22 & 2.023 & 0.004555 & 0.0093 & $\begin{array}{l}8.35 \mathrm{E}- \\
05\end{array}$ & 0.0026 & $\begin{array}{l}5.85 \mathrm{E}- \\
05\end{array}$ & 0.011 & $\begin{array}{l}9.8 \\
05\end{array}$ \\
\hline
\end{tabular}

- XRD analyses identify the powder as $\mathrm{PuO}_{2}$.

- Forensic examinations of the microscope image of the plant seed by NLEA investigators conclude the seed is of the flowering plant "sanguinis elius". This plant is native to northern territories to as far south as Chicoland.

- Based upon the picture of evidence piece 3.3. you provided NLEA investigators, they have been able to match the handwriting of the suspect in custody with the handwriting on the note.

- The note was also translated. Investigators would like to know if you believe there is any significance to the technical information provided in the translated note. 


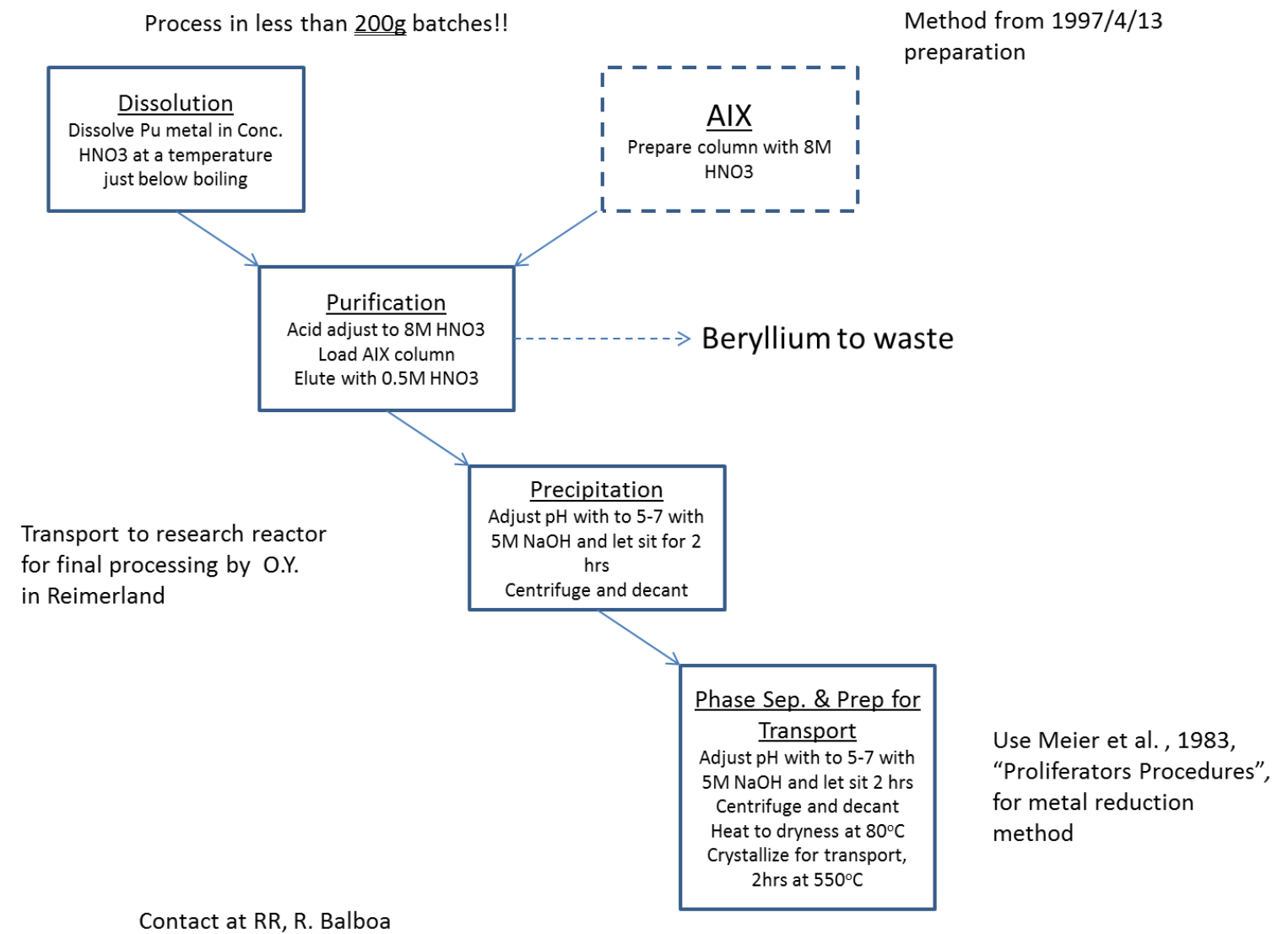

MC-ICP-MS will conclusively exclude the possibility that the material seized came from Reimerland inventory. XRD analysis will confirm the material is $\mathrm{PuO}_{2}$.]

\section{SBE 9: GICNT Engagement of Holdings within Chicoland and Yosemland}

The Law enforcement has asked your assistance in helping to draft a request to be sent through diplomatic channels to representatives in bordering countries Chicoland and Yosemland in order to determine if they may have holdings that match that of item 3.1.

[A request should be generated asking both countries to check their inventories of materials matching that of the materials seized by authorities in Reimerland. Yosemland officials respond with the response letters shown in Appendix H. A summary of the results of the entire SBE is provided in Appendix I.] 


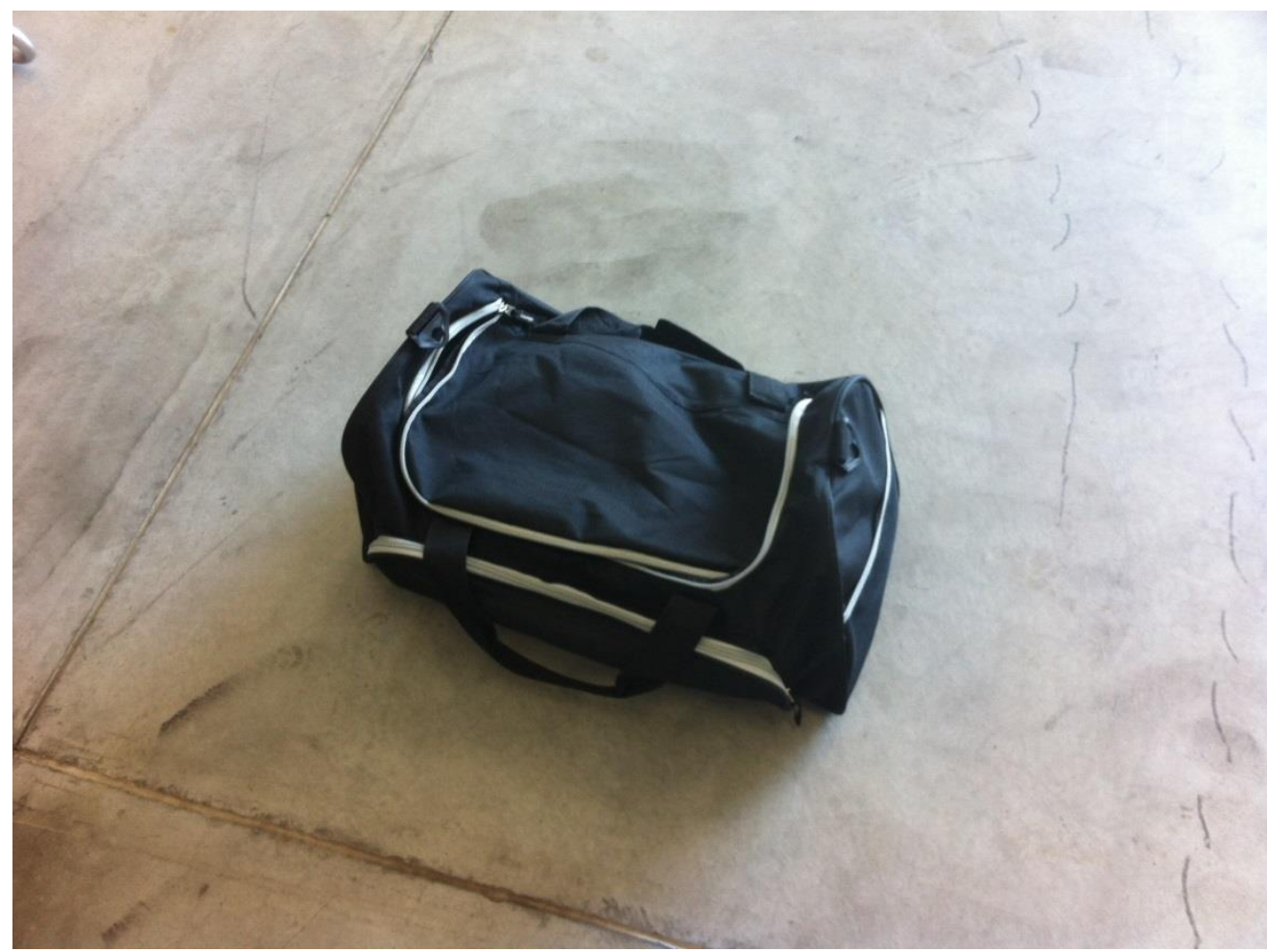

Figure 1. Black Duffle bag containing suspect radioactive material of interest. 


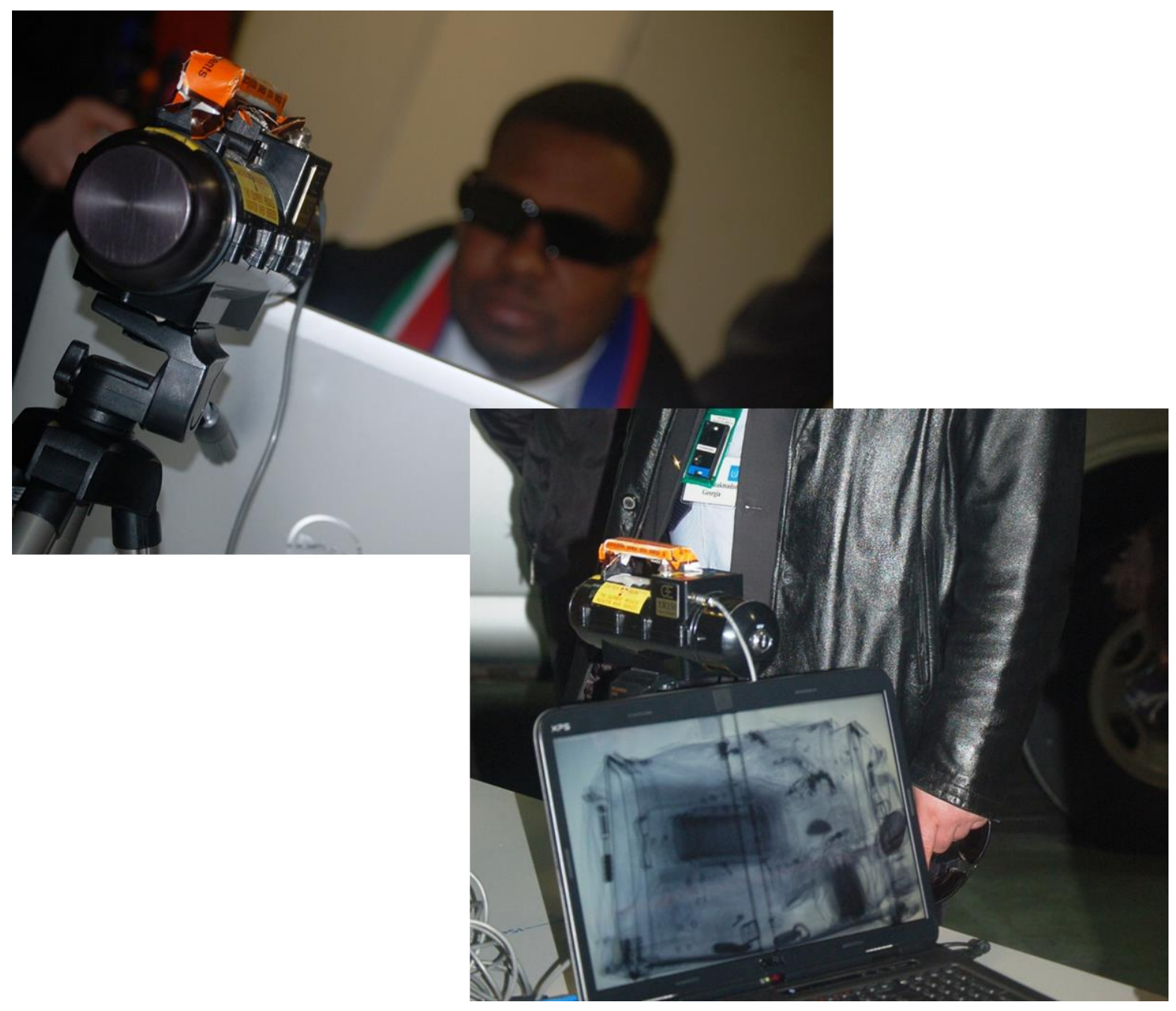

Figure 2. 3-D radiography of black duffle to enable "render safe" and movement of the entire bag and its contents to NLEA Reimerland Radiation Laboratory (RRL) for further processing. 


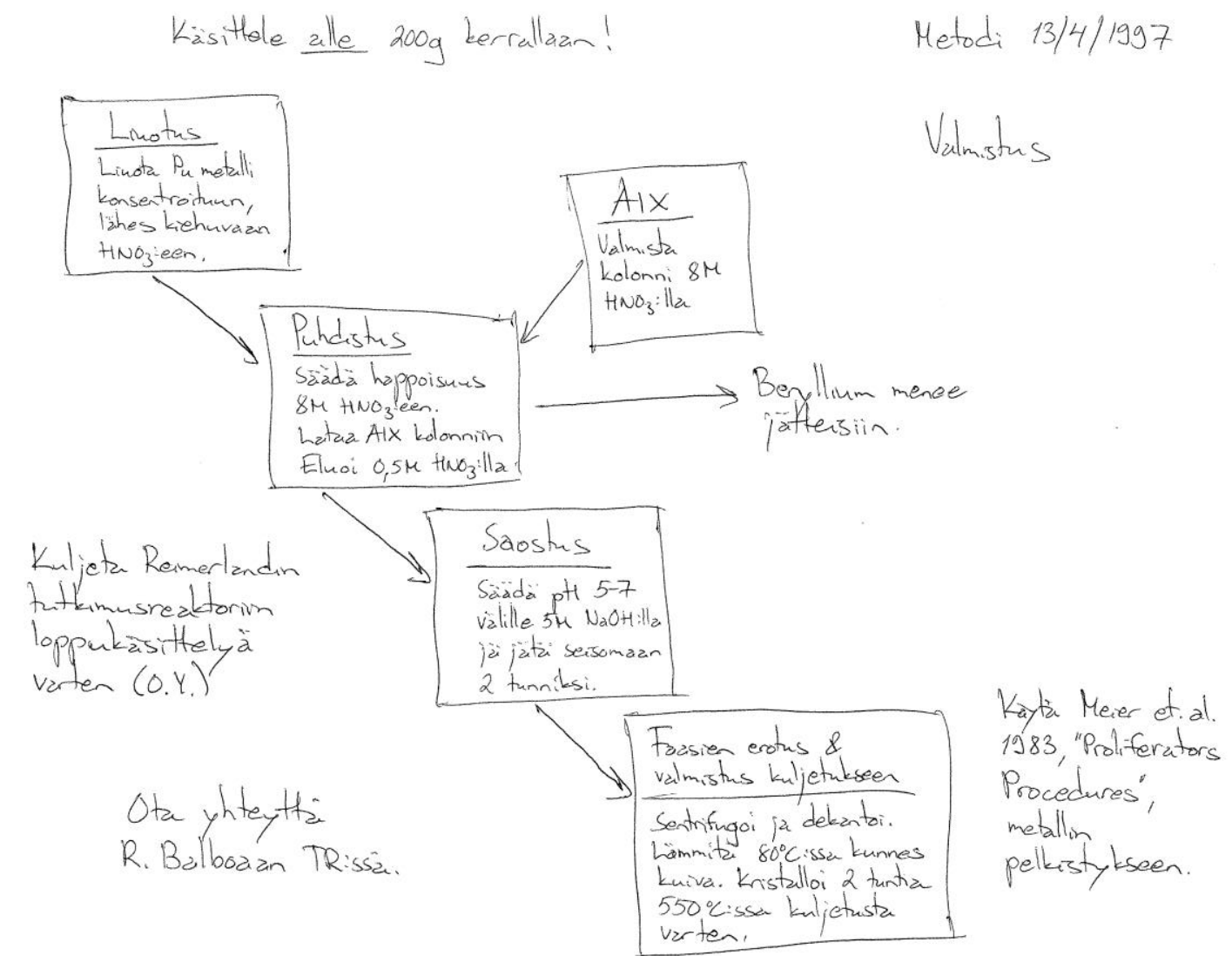

Figure 3. Evidence Piece 3.3. 


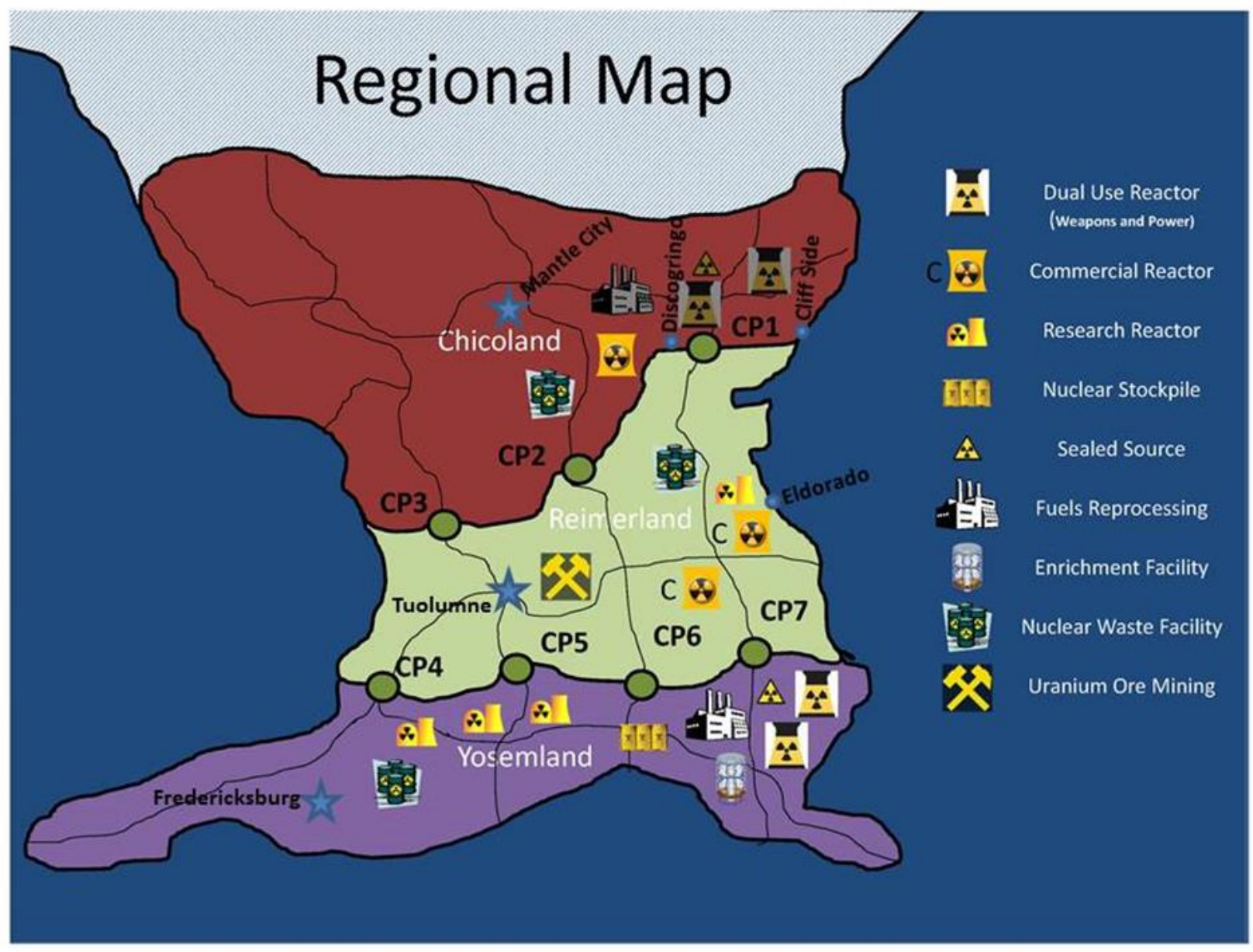

\section{REIMERLAND DOSSIER}

\section{Government Type: Social Democracy}

Geography: Reimerland is a small country of 153,085 square kilometers, located on an isthmus with land borders to the north and south. Reimerland is flat with winding brackish river systems that feed numerous coastal inlets. These river systems frequently overflow during the rainy season producing wide sweeping grasslands and plush forests. Reimerland has a well-established power grid, adequate supplies of potable water, and infrastructure to manage air and water quality. Unemployment is relatively low at approximately $7 \%$.

\section{Population: 14 million}

\section{GDP (purchasing power parity): \$250 billion}

Industries: Coal, hydro- electric power, timber, ferrous and nonferrous metals, machinery and transport equipment, chemicals, food processing. Reimerland operates one Pressurized Water Reactor (PWR) reactor for electricity generation and as a resource for various fields of science and education in the nuclear sciences. The reactor incorporates facilities for radioisotope production for medical, industrial and agricultural purposes.

International NF Community: In 2009 Reimerland became an active member of the International NF Community, attending the annual International Technical Working Group for NF meetings and participating in GICNT NF Working Group meetings. Reimerland has a history of close cooperation with 
the International Atomic Energy Agency (IAEA) as a member of the Analytical Laboratories for the Measurement of Environmental RadioActivity (ALMERA) network since 1998 and routine reporting to the Incident and Trafficking Data Base (ITDB) of materials that are found out of regulatory control. In 2011, Reimerland hosted an IAEA regional workshop on "Radiological Crime Scene Management" and have offered to host an "Introduction to Nuclear Forensics Workshop" in the near future

Nuclear Forensics Capabilities: The National Law Enforcement Agency (NLEA) has a specialized facility (Reimerland Radioanalytical Laboratory - RRL), specialized crime scene teams trained for collecting, categorizing, packaging, and transporting radioactive materials and maintains a memorandum of understanding with the National Environmental Radiation Laboratory (NERL) part of the Reimerland Institute of Technology. The laboratory provides analytical services during forensics investigations.

Known Domestic Material: Commercial material and small amounts of academic material, including fresh and spent nuclear fuel, sealed sources and medical radioisotopes.

Law Enforcement/Legal Environment: Respect for law enforcement is common. Some violent domestic groups have migrated to Reimerland in recent years advocating anarchy and antigovernment sentiments in support of a host of issues including; animal rights, and anti- and pro-nuclear energy and nuclear weapons. The splinter group "Oppose Y" supports the agenda of developing a nuclear weapons program to balance power in the region with its pro-nuclear neighboring state Yosemland. Reimerland has a history of settling legal disputes through the court system and using case law for precedence in deciding matters of law and of accepting physical evidence if presented at trial. Local court decisions can be appealed at the national level via the Supreme Court. Reimerland is a signatory of the Nuclear Nonproliferation Treaty (NPT), the Convention on the Physical Protection of Nuclear Materials (CPPNM), and the International Convention on the Suppression of Acts of Nuclear Terrorism. Reimerland actively implements UNSCR 1540, among other treaties and international agreements. Reimerland has laws that criminalize the unauthorized possession of more than 500 milligrams of $\mathrm{Pu}$ or $\mathrm{U}$ enriched with respect to ${ }^{235} \mathrm{U}$ above natural abundance.

Political Climate: Considered somewhat stable, with moderate to high turnout for local and national elections. Nuclear power and nuclear weapons are being publicly debated; currently no new nuclear facilities have been approved.

Public Health Infrastructure: Widely available private coverage and government subsidized care for low income/unemployed residents.

The Reimerland Ministry of Health has approved the National Environmental Radiation Laboratory (NERL) to provide radioanalytical services to the government and commercial entities. Radiochemical analyses are performed for alpha, beta and gamma emitting radionuclides in a wide range of matrices such as soil, sediment, sludge, water, food, smear test, fauna and flora. The laboratory has its own Quality Assurance (QA) and Management procedures which are accredited to ISO/IEC 17025:2005 by the Reimerland Department of Standards for the analysis of gamma emitting radionuclides. For alpha and beta emitting radionuclides, the laboratory regularly participates in inter-laboratory analysis and proficiency tests organized by International Atomic Energy Agency (IAEA) and other competent international bodies.

Academic Infrastructure: High rate of literacy and strong educational tradition with post- secondary education offered at low or no cost. Reimerland has a strong university system which emphasizes engineering and the physical sciences. There is significant funding from the government for environmental research within the university system. Reimerland Institute of Technology maintains an analytical chemistry laboratory that provides analysis services to government agencies. Currently, the laboratory is equipped with various analytical instruments, including gamma spectrometers, Inductively Couple Plasma Mass Spectrometer (ICP-MS), Inductively Couple Plasma Optical Emission Spectrometer (ICP-OES), Gas Chromatography Mass Spectrometer (GC-MS), Ion Chromatograph, Luminescence 
Spectrometer and CHNS elemental analyzer. The laboratory adopts good quality control and quality assurance practices in order to provide high quality output, which meets international standards.

\section{Table A-1. Analytical capabilities available to Reimerland National Law Enforcement Agency. \\ RRL, Natl. Law Enforcement Agency \\ NERL, Reimerland Institute of Technology}

\author{
Alpha Spectrometry \\ High Res. Gamma Spectrometry \\ 3-D X-Ray Radiography \\ Hand Held field portable detectors \\ Low Res. NaI Gamma Spectrometry
}

\author{
Gamma Spectrometry \\ ICP-Mass Spectrometry (ICP-MS) \\ ICP-Optical Em. Spectrometry (ICP-OES) \\ Gas Chromatography-MS (GC-MS) \\ Ion Chromatography \\ Luminescence Spectrometer \\ CHNS Elemental Analyzer
}

\section{CHICOLAND DOSSIER}

Government Type: Democracy

Geography: Chicoland is a country of 267,332 square kilometers with few natural resources and modest agricultural lands. Chicoland is a former nuclear weapons state, having closed its weapons production reactors, its reprocessing and sealed-source manufacturing facilities, its medical isotope production, and nuclear waste facilities. However, Chicoland retains one PWR for domestic power generation. This single power reactor provides domestic power to the most populated centers of manufacturing and commerce along the border with Reimerland. Unemployment has risen to $19 \%$ in recent years. The economic downturn associated with rising unemployment has dramatically decreased the GDP of this country.

Population: 28 million

GDP (purchasing power parity): \$113.2 billion

Industries: Agriculture provides a modest living for growers and fruit producers in the central region of Chicoland. Manufacturing industries includes textile mills, electronic parts assembly, well-pump manufacture and repair. Chicoland also has a large fishing industry.

International NF Community: Chicoland became a former nuclear weapons state in 1989 and has actively participated in the International NF Community in recent years (ITWG and GICNT). Chicoland has stood up a basic NF capability but it lags in its technical capabilities, relative to its neighbors to the South. Chicoland and Reimerland have formed a regional alliance for investigating nuclear smuggling cases. Chicoland attends the annual International Technical Working Group meetings and has joined the International Atomic Energy Agency (IAEA) as a member state. Chicoland continues to build its NF technical expertise and analytical capabilities.

Nuclear Forensics Capabilities: The Federal Law Enforcement Agency (FLEA) of Chicoland has limited capabilities for crime scene management and collecting, categorizing, packaging, and transporting radioactive materials. The agency does, however, maintain a memorandum of understanding with Reimerlands NLEA that enables them to utilize forensic capabilities represented by their partner.

Known Domestic Material: Chicoland was a nuclear weapons state with reprocessing capabilities until 1989, when it transferred its weapons materials to Yosemland. As part of the weapons program they manufactured medical isotopes and sealed-sources including Pu/Be sources. Many activities connected to the weapons programs languished when the decision was made to terminate its nuclear weapons program. 
One PWR remains for domestic power production. Nuclear fuel is sourced from Yosemland and spent nuclear fuel is shipped to Yosemland for reprocessing and disposal.

Law Enforcement/Legal Environment:

Chicoland is a signatory of the Nuclear Nonproliferation Treaty (NPT), the Convention on the Physical Protection of Nuclear Materials (CPPNM), and the International Convention on the Suppression of Acts of Nuclear Terrorism. Chicoland actively implements UNSCR 1540, among other treaties and international agreements. Chicoland has laws that criminalize the unauthorized possession of more than 500 milligrams of weapons useable nuclear material $\left(>20 \%{ }^{235} \mathrm{U},{ }^{233} \mathrm{U}, \mathrm{Pu}\right)$. In recent years, Chicoland authorities have seen an increase in nuclear smuggling cases thought to be associated with the lack of security surrounding its historic weapons production facilities.

Political Climate: Adoption of the nuclear disarmament accord (NDA) was widely supported and ratified by federal legislators in 1989. Public support for the NDA was heralded in local and national elections with the exception of a small terrorist group known as the "Oppose Y", referencing their disdain for Yosemland. This group pushed to maintain a strong nuclear weapons program to balance power in the region with Yosemland. Chicoland reached an agreement with Yosemland for reprocessing of future SNF from its civilian power reactor. Disarmament and dismantling of nuclear weapons began in 1992 but dismantling has been slowed due to lack of resources. All materials slated for the weapons stockpile within Chicoland were transferred to Yosemland by 1992. However, significant amounts of SNM contained within the now defunct commercial industries associated with the weapons program remain safeguarded in country. Nuclear power is publically supported but no new nuclear facilities have been licensed. 


\section{YOSEMLAND DOSSIER}

\section{Government Type: Republic}

Geography: Yosemland shares its northern border with Reimerland and is also a small country of 172,381

square kilometers. Yosemland's well-established nuclear power infrastructure is located in this region, as is most of the commercial and manufacturing base. The Western region of Yosemland is steeply mountainous with several rivers fed by abundant rainfall. The rivers provide irrigation for agricultural lands in southern Yosemland. Agriculture, although sustainable, employs only a small percentage of the citizens in this populous industrial and manufacturing society. Unemployment averages nearly $10 \%$ outside of the growing season.

Population: 26 million

GDP (purchasing power parity): \$373.4 billion

Industries: Industrial manufacturing includes integrated circuit production, software development, metalfabrication for automotive and aerospace components, medical isotope production, and some food processing. Agricultural exports include potatoes, corn, sheep, olives, olive oil, and fish. Two stateowned dual-purpose graphite moderated reactors provide commercial power and $\mathrm{Pu}$ material for its weapons stockpile. A small portion of this material is diverted for producing commercial grade neutron sources. Three other research reactors produce various medical isotopes. With the exception of sourcing its $\mathrm{U}$ ore from Reimerland, Yosemland maintains full U and Pu fuel cycles. Spent nuclear fuel generated in country and accepted from Chicoland and Reimerland is reprocessed and wastes isolated at dedicated facilities. Yosemland supplies all of the LEU fuel used by Reimerland and Chicoland.

International NF Community: Yosemland does not actively participate in meetings and exercises of the nuclear forensics community. The state ownership of the three research reactors and the weapons development programs leaves the nuclear expertise of Yosemland somewhat isolated from the international community.

Nuclear Forensics Capabilities: Representatives from the National Justice Branch (NJB) have attended GICNT and ITWG meetings sporadically but have never participated in table-top or materials exercises.

Known Domestic Material: With the exception of having an indigenous supply of uranium ore, Yosemland maintains full uranium and plutonium fuel cycles for nuclear weapons production. Medical isotopes are manufactured at the three research reactors. A portion of the weapons product from its dualuse reactors is also diverted to produce commercial grade neutron sources. Nuclear wastes are stored at dedicated facilities.

\section{Law Enforcement/Legal Environment:}

Yosemland laws do not specifically criminalize the unauthorized possession of weapons usable (>20\% ${ }^{235} \mathrm{U}, \mathrm{Pu}$ ) nuclear material.

Political Climate: Yosemland reached an agreement with Reimerland in 1992 for uranium ore to supply their research reactors in exchange for purchasing and recycling agreement for its fresh and spent nuclear fuel for 30 years. Yosemland was instrumental in convincing Chicoland to give up its weapons program in 1989 by offering to accept the transfer of Chicoland's remaining weapons stockpile. Nuclear power is publically supported but no new nuclear facilities have been licensed in the last 10 years.

Public Health Infrastructure: Although the state operated health care system provides medical coverage for its citizens the level of care is often very basic. Private medical insurance is too expensive for the vast majority of citizens.

The Yosemland Health Department provides oversight of medical isotope production and sealed source production and management. 


\section{APPENDIX B: RESULTS EXPECTED FROM SBE 2.}

Participants should send evidence pieces 1 and 2 that were not contaminated with radioactivity off to the NLEA forensics crime lab for further processing.

- Pictures of all items of evidence contained in zip-lock bag \#3 and \#4.

- Microscopy pictures of 3.1.1. and 3.2.

- Send pictures to law enforcement for further processing.

- Mass measurements of 3.1.1, 3.2 and 4.1.

- Density measurements of 3.1.1., and 4.1.

Evidence Item

Mass

Density

3.1.1.

N/A

4.1. 


\section{APPENDIX C: EXPECTED RESULTS FROM SBE 4.}

- Evidence piece 3.1.1. contains low burnup plutonium.

- Evidence piece 4.1 contains the radioactive isotope ${ }^{133} \mathrm{Ba}$. Concentration and form inconsistent with a sealed industrial source. May have been used to "mask" Pu signature.

- Summary of expected gamma results generated from FRAM:

$\begin{array}{lllllllllllll}\text { Evidence } & { }^{238} \mathbf{P u} & 1-\sigma & { }^{239} \mathbf{P u} & \mathbf{1}-\sigma & { }^{240} \mathbf{P u} & \mathbf{1 - \sigma} & { }^{241} \mathbf{P u} & \mathbf{1 - \sigma} & { }^{242} \mathbf{P u} & \mathbf{1 - \sigma} & { }^{241} \mathrm{Am} & \mathbf{1 - \sigma} \\ \text { Piece } & (\%) & & (\%) & & (\%) & & (\%) & & (\%) & & (\%) & \\ \text { 3.1.1. } & 0.0019 & 0.0013 & 98.12 & 0.21 & 1.86 & 0.21 & 0.0093 & 0.0002 & 0.0019 & 0.0007 & 0.0098 & 0.0034\end{array}$




\section{APPENDIX D: EXPECTED RESULTS FROM SBE 5.}

- 3.3. contains $\mathrm{Pu}$ that is consistent with that of 3.1.1.

- Summary of expected alpha spectrometry results for 3.1.1.:

\begin{tabular}{|c|c|c|c|c|c|c|c|}
\hline $\begin{array}{l}\text { Evidence } \\
\text { Piece }\end{array}$ & $\begin{array}{l}{ }^{238} \mathrm{Pu} \\
(\mathrm{Bq})\end{array}$ & $1-\sigma$ & $\begin{array}{l}{ }^{239,240} \mathrm{Pu} \\
(\mathrm{Bq})\end{array}$ & $1-\sigma$ & $\begin{array}{l}{ }_{(\%)}^{241} \mathrm{Am} \\
(\%)\end{array}$ & $1-c$ & $\begin{array}{l}{ }^{238} \mathrm{Pu} / \\
{ }^{239,240} \mathrm{Pu} \\
\text { (mass } \\
\text { ratio) }\end{array}$ \\
\hline
\end{tabular}

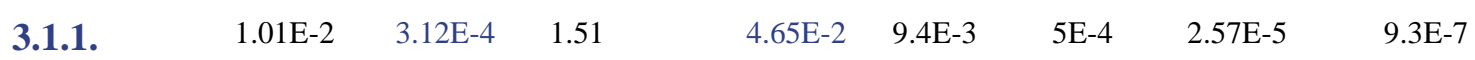


APPENDIX E: EXPECTED RESULTS FROM SBE 6.

- Elimination of all sources not containing Pu

- Elimination of SNF

- Elimination of Y-1 thru Y-5 and C-1 and C-2 based upon gamma and alpha analyses. A complete breakdown of comparisons of PuBe sources in the Reimerland inventory based upon alpha and gamma analyses is shown below.

\section{Gamma Results}

\begin{tabular}{|c|c|c|c|c|c|c|c|}
\hline Sample & ${ }^{238} \mathrm{Pu}$ & ${ }^{239} \mathrm{Pu}$ & $240 \mathrm{Pu}$ & $\begin{array}{l}{ }^{241} \mathrm{Pu} \\
(+241 \mathrm{Am})\end{array}$ & ${ }^{242} \mathrm{Pu}$ & $\begin{array}{l}\mathrm{Pu} / \mathrm{Am} \\
\text { Age }\end{array}$ & $\begin{array}{l}\text { Am/Np } \\
\text { Age }\end{array}$ \\
\hline $\mathrm{C} 1$ & $\sqrt{ }$ & $\sqrt{ }$ & $\sqrt{ }$ & $\sqrt{ }$ & $\sqrt{ }$ & $\sqrt{ }$ & - \\
\hline $\mathrm{C} 2$ & $\sqrt{ }$ & $\sqrt{ }$ & $\sqrt{ }$ & $\sqrt{ }$ & $\sqrt{ }$ & $\sqrt{ }$ & - \\
\hline R1 & $\sqrt{ }$ & $\sqrt{ }$ & $\sqrt{ }$ & $\sqrt{ }$ & $\sqrt{ }$ & $\sqrt{ }$ & - \\
\hline Y1 & $\sqrt{ }$ & $\chi$ & $\chi$ & $\sqrt{ }$ & $\sqrt{ }$ & $\sqrt{ }$ & - \\
\hline Y2 & $\sqrt{ }$ & $\chi$ & $\chi$ & $\sqrt{ }$ & $\sqrt{ }$ & $\sqrt{ }$ & - \\
\hline Y3 & $\sqrt{ }$ & $\chi$ & $\chi$ & $\sqrt{ }$ & $\sqrt{ }$ & $\sqrt{ }$ & - \\
\hline Y4 & $\sqrt{ }$ & $\chi$ & $\chi$ & $\sqrt{ }$ & $\sqrt{ }$ & $\sqrt{ }$ & - \\
\hline Y5 & $\sqrt{ }$ & $\chi$ & $\chi$ & $\sqrt{ }$ & $\sqrt{ }$ & $\sqrt{ }$ & - \\
\hline Y6 & $\sqrt{ }$ & $\sqrt{ }$ & $\sqrt{ }$ & $\sqrt{ }$ & $\sqrt{ }$ & $\sqrt{ }$ & - \\
\hline Y7 & $\sqrt{ }$ & $\sqrt{ }$ & $\sqrt{ }$ & $\sqrt{ }$ & $\sqrt{ }$ & $\sqrt{ }$ & - \\
\hline Y8 & $\sqrt{ }$ & $\sqrt{ }$ & $\sqrt{ }$ & $\sqrt{ }$ & $\sqrt{ }$ & $\sqrt{ }$ & - \\
\hline
\end{tabular}


APPENDIX F: EXPECTED RESULTS FROM SBE 7.

- Elimination of Y-6 and Y-8 based upon ICP-MS analyses. A complete breakdown of comparisons of PuBe sources in the Reimerland inventory based upon ICP-MS analyses is shown below.

\section{Alpha Results}

\begin{tabular}{|l|c|c|c|c|c|c|c|}
\hline Sample & $238 \mathrm{Pu}$ & ${ }^{239} \mathrm{Pu}$ & ${ }^{240} \mathrm{Pu}$ & $\begin{array}{l}{ }^{241} \mathrm{Pu} \\
(+241 \mathrm{Am})\end{array}$ & $\begin{array}{l}{ }^{242} \mathrm{Pu} \\
\mathrm{Pu} / \mathrm{Am} \\
\mathrm{Age}\end{array}$ & $\begin{array}{l}\text { Am/Np } \\
\text { Age }\end{array}$ \\
\hline C1 & - & - & - & - & - & $\chi$ & - \\
\hline C2 & - & - & - & - & - & $\chi$ & - \\
\hline R1 & - & - & - & - & - & $\sqrt{ }$ & - \\
\hline Y1 & - & - & - & - & - & $\sqrt{ }$ & - \\
\hline Y2 & - & - & - & - & - & $\chi$ & - \\
\hline Y3 & - & - & - & - & - & $\chi$ & - \\
\hline Y4 & - & - & - & - & - & $\chi$ & - \\
\hline Y5 & - & - & - & - & - & $\sqrt{ }$ & - \\
\hline Y6 & - & - & - & - & - & $\sqrt{ }$ & - \\
\hline Y7 & - & - & - & - & - & $\sqrt{ }$ & - \\
\hline Y8 & - & - & - & - & - & $\sqrt{ }$ & - \\
\hline
\end{tabular}


APPENDIX G: EXPECTED RESULTS FROM SBE 8.

- Elimination of all remaining PuBe sources in Reimerland inventory based upon MC-ICP-MS analyses. A complete breakdown of comparisons of PuBe sources in the Reimerland inventory based upon MC-ICP-MS analyses is shown below.

- XRD confirms Pu powder is in the form of $\mathrm{PuO}_{2}$.

\section{ICP-MS Results}

\begin{tabular}{|c|c|c|c|c|c|c|c|}
\hline Sample & ${ }^{238} \mathrm{Pu}$ & ${ }^{239} \mathrm{Pu}$ & $240 \mathrm{Pu}$ & $\begin{array}{l}{ }^{241} \mathrm{Pu} \\
(+241 \mathrm{Am})\end{array}$ & ${ }^{242} \mathrm{Pu}$ & $\begin{array}{l}\text { Pu/Am } \\
\text { Age }\end{array}$ & $\begin{array}{l}\text { Am/Np } \\
\text { Age }\end{array}$ \\
\hline C1 & $\sqrt{ }$ & $\sqrt{ }$ & $\sqrt{ }$ & $\sqrt{ }$ & $\sqrt{ }$ & $\sqrt{ }$ & - \\
\hline $\mathrm{C} 2$ & $\sqrt{ }$ & $\sqrt{ }$ & $\sqrt{ }$ & $\sqrt{ }$ & $\sqrt{ }$ & $\sqrt{ }$ & - \\
\hline $\mathrm{R} 1$ & $\sqrt{ }$ & $\sqrt{ }$ & $\sqrt{ }$ & $\sqrt{ }$ & $\sqrt{ }$ & $\sqrt{ }$ & - \\
\hline Y1 & $\sqrt{ }$ & $x$ & $\chi$ & $\sqrt{ }$ & $\sqrt{ }$ & $\chi$ & - \\
\hline Y2 & $\sqrt{ }$ & $\chi$ & $\chi$ & $\sqrt{ }$ & $\sqrt{ }$ & $\chi$ & - \\
\hline Y3 & $\sqrt{ }$ & $\chi$ & $\chi$ & $\sqrt{ }$ & $\sqrt{ }$ & $\chi$ & - \\
\hline Y4 & $\sqrt{ }$ & $\chi$ & $\chi$ & $\sqrt{ }$ & $\chi$ & $\chi$ & - \\
\hline Y5 & $\sqrt{ }$ & $\chi$ & $\chi$ & $\sqrt{ }$ & $\sqrt{ }$ & $\sqrt{ }$ & - \\
\hline Y6 & $\sqrt{ }$ & $\sqrt{ }$ & $\sqrt{ }$ & $\sqrt{ }$ & $\sqrt{ }$ & $\chi$ & - \\
\hline Y7 & $\sqrt{ }$ & $\sqrt{ }$ & $\sqrt{ }$ & $\sqrt{ }$ & $\sqrt{ }$ & $\sqrt{ }$ & - \\
\hline Y8 & $\sqrt{ }$ & $\sqrt{ }$ & $\sqrt{ }$ & $\sqrt{ }$ & $\chi$ & $\sqrt{ }$ & - \\
\hline
\end{tabular}


MC-ICP-MS Results

\begin{tabular}{|c|c|c|c|c|c|c|c|}
\hline Sample & ${ }^{238} \mathrm{Pu}$ & ${ }^{239} \mathrm{Pu}$ & ${ }^{240} \mathrm{Pu}$ & $\begin{array}{l}{ }^{241} \mathrm{Pu} \\
(+241 \mathrm{Am})\end{array}$ & ${ }^{242} \mathrm{Pu}$ & $\begin{array}{l}\text { Pu/Am } \\
\text { Age }\end{array}$ & $\begin{array}{l}\text { Am/Np } \\
\text { Age }\end{array}$ \\
\hline C1 & $\sqrt{ }$ & $\sqrt{ }$ & $\sqrt{ }$ & $\sqrt{ }$ & $\sqrt{ }$ & $x$ & - \\
\hline $\mathrm{C} 2$ & $\sqrt{ }$ & $\sqrt{ }$ & $\sqrt{ }$ & $\sqrt{ }$ & $\sqrt{ }$ & $x$ & - \\
\hline R1 & $\sqrt{ }$ & $\sqrt{ }$ & $\sqrt{ }$ & $\sqrt{ }$ & $\sqrt{ }$ & $\chi$ & - \\
\hline Y1 & $\sqrt{ }$ & $x$ & $x$ & $\sqrt{ }$ & $\sqrt{ }$ & $\chi$ & - \\
\hline Y2 & $\sqrt{ }$ & $\chi$ & $x$ & $\sqrt{ }$ & $\sqrt{ }$ & $\chi$ & - \\
\hline Y3 & $\sqrt{ }$ & $\chi$ & $\chi$ & $\sqrt{ }$ & $\sqrt{ }$ & $\chi$ & - \\
\hline Y4 & $\sqrt{ }$ & $x$ & $x$ & $\sqrt{ }$ & $\chi$ & $\chi$ & - \\
\hline Y5 & $\sqrt{ }$ & $\chi$ & $\chi$ & $\sqrt{ }$ & $\sqrt{ }$ & $\sqrt{ }$ & - \\
\hline Y6 & $\sqrt{ }$ & $\sqrt{ }$ & $\sqrt{ }$ & $\sqrt{ }$ & $\sqrt{ }$ & $\chi$ & - \\
\hline Y7 & $\sqrt{ }$ & $\chi$ & $\sqrt{ }$ & $\sqrt{ }$ & $\sqrt{ }$ & $\sqrt{ }$ & - \\
\hline Y8 & $\sqrt{ }$ & $\sqrt{ }$ & $\chi$ & $\sqrt{ }$ & $\chi$ & $\sqrt{ }$ & - \\
\hline
\end{tabular}




\section{APPENDIX H: DATA INJECT \#3 - RESPONSE LETTERS FROM CHICOLAND AND \\ YOSEMILAND OFFICIALS}

Logan Leigh

Foreign Minister

Federation of Yosemland

Salisbury, Yosemland

November 7th, 2013

Adam Nicole

Ambassador of International Relations

Republic of Reimerland

Beta City, Bowline Province, Reimerland

Dear Ambassador Nicole:

Thank you for notifying Yosemland of your recent security issues related to the seizure of plutonium in your country. As you know, Yosemland maintains a robust security of its nuclear holdings, the content of which is held as a national secret. Therefore it was no surprise to us, after a cursory review of the analytical data you sent us, that we concluded with the utmost confidence that this material did not originate from our inventory. We wish you luck in your investigation and would appreciate being apprised of any future developments in this case.

Sincerely,

Logan Leigh 
Evanni Michealson

Secretary of Foreign Affairs

Chicoland Federation

Mantle City, Mountain Home Region, Chicoland

November 7th, 2013

Adam Nicole

Ambassador of International Relations

Republic of Reimerland

Beta City, Bowline Province, Reimerland

\section{Dear Ambassador Nicole:}

I wish to thank you for informing Chicoland officials of the recent seizure event in Reimerland involving the attempted smuggling of plutonium across the northern border with Chicoland and want to convey the full support of my office in your endeavor to bring those responsible for this act to justice. As you may know, Chicoland has experienced a rise in similar events within our borders in recent years and I am concerned this latest event in Reimerland may be related to some of those events. For full disclosure I provide a summary of seizures over the past two decades in Chicoland that involved plutonium.

December $12^{\text {th }}$, 1995: A man was stopped during a routine traffic stop for an unrelated traffic violation. Upon a search of his vehicle, authorities uncovered $2.3 \mathrm{~kg}$ of plutonium metal.

Based upon information we obtained through questioning of the suspect, ensuing undercover investigations were able to recover another $3.5 \mathrm{~kg}$ of plutonium metal on February $2^{\text {nd }}, 1996$, from an abandoned warehouse in the southern city of Discogringo. We believe that material came from the same source as that material recovered on December $12^{\text {th }}, 1995$.

June $1^{\text {st }}$, 1999: Chicoland authorities seized $1.1 \mathrm{~kg}$ of plutonium powder after they were contacted by a concerned citizen. This individual runs a fishing charter and became suspicious when he was hired to transit five individuals with a large amount of equipment by boat to the Reimerland port of Cliffside. We believe this seizure is unrelated to those that occurred in 1995 and 1996 since the form of this material (powder) and the isotopic composition were significantly different.

August $14^{\text {th }}$, 2005: Chicoland authorities seized $1.3 \mathrm{~kg}$ of Pu powder at an airport just outside the Country capital of Mantle City from an individual attempting to board an international flight to the tourist city of Eldorado, Reimerland. A subsequent search of his residence uncovered another $1 \mathrm{~kg}$ of similar powder.

March $30^{\text {th }}, 2009$ : Intelligence sting operations focused on the terror group "Oppose Y" resulted in the seizure of $1.4 \mathrm{~kg}$ of $\mathrm{Pu}$ powder (similar to the 1999 and 2005 seizures).

May $22^{\text {nd }}, 2010$ : Intelligence sting operations focused on the terror group "Oppose Y" resulted in the seizure of $903 \mathrm{~g}$ of Pu powder (similar to the 1999, 2005 and 2009 seizures). 
The material recently seized in Reimerland looks strikingly similar to some of the materials seized in our Country starting in 1999, which are all oxide powders with similar isotopic composition to your materials. This material, however, appears to be significantly different than the Pu metal seized within our country in 1995 and 1996. We believe we know where the Pu metal originated from. We suspect this material was historically in Chicoland's nuclear inventory up to 1994. In that year, $27 \mathrm{~kg}$ of special nuclear material (nominally $98 \%$ Pu metal alloyed with Beryllium) was stolen from a facility that used to make commercial neutron sources by diverting a small portion of the country's product materials destined for its weapons stockpile. That facility closed down in 1992 after the country decided to abandon its weapons program in 1989. Since 1992, all $112 \mathrm{~kg}$ of the remaining Pu-Be neutron source inventory was stored and safeguarded in place until the 1994 incident. However, we still do not know the origin of the $\mathrm{Pu}$ oxide powders that have been the focus of more recent seizures within our country. Please let us know if you concur with our assessment.

The trafficking of special nuclear material is of the highest interest to Chicoland authorities. As such we would appreciate the opportunity to work with Reimerland authorities to bring those responsible to justice.

Sincerely,

\section{Evanni Michealson}


Chicoland

Seizures

$\begin{array}{lllllllll} & \text { Pu-238 } & \begin{array}{l}\text { Pu- } \\ 239\end{array} & \begin{array}{l}\text { Pu- } \\ 240\end{array} & \text { Pu-241 } & \text { Pu-242 } & \begin{array}{l}\text { Am- } \\ 241\end{array} & \text { Form } & \begin{array}{l}\text { Total } \\ \text { Recovered } \\ (\text { Kg) }\end{array} \\ 1995 & 0.0194 & 97.3 & 2.05 & 0.00600 & 0.00202 & 0.0134 & \text { Metal } & 2.3 \\ 1996 & 0.0184 & 97.5 & 2.01 & 0.00620 & 0.00194 & 0.0138 & \text { Metal } & 3.5 \\ 1999 & 0.0200 & 97.9 & 1.93 & 0.00910 & 0.00198 & 0.0112 & \text { Oxide } & 1.1 \\ 2005 & 0.0192 & 97.5 & 2.05 & 0.00840 & 0.00204 & 0.0110 & \text { Oxide } & 2.3 \\ 2009 & 0.0182 & 97.8 & 1.91 & 0.00900 & 0.00198 & 0.0110 & \text { Oxide } & 1.4 \\ 2010 & 0.0190 & 97.6 & 1.99 & 0.00902 & 0.00199 & 0.0108 & \text { Oxide } & 0.903\end{array}$




\section{APPENDIX I: SUMMARY OF THE SCENARIO BASED EXERCISE}

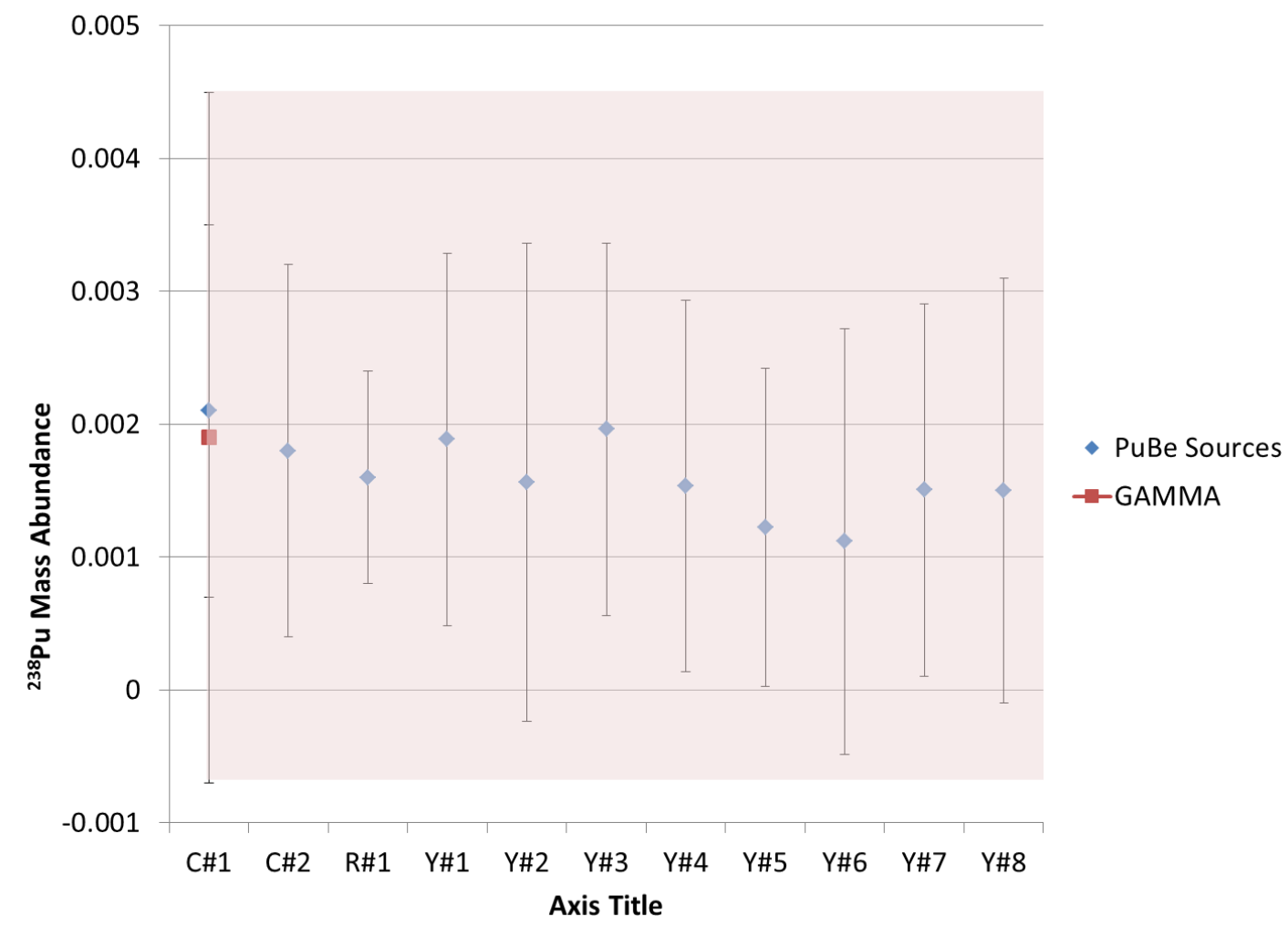

Figure I-1: Comparison of ${ }^{238} \mathrm{Pu}$ mass abundance with PuBe sources in Reimerland inventory. Light red shaded area represents the $95 \%$ confidence interval around the datapoint for the unknown measured by gamma ray spectrometry. 


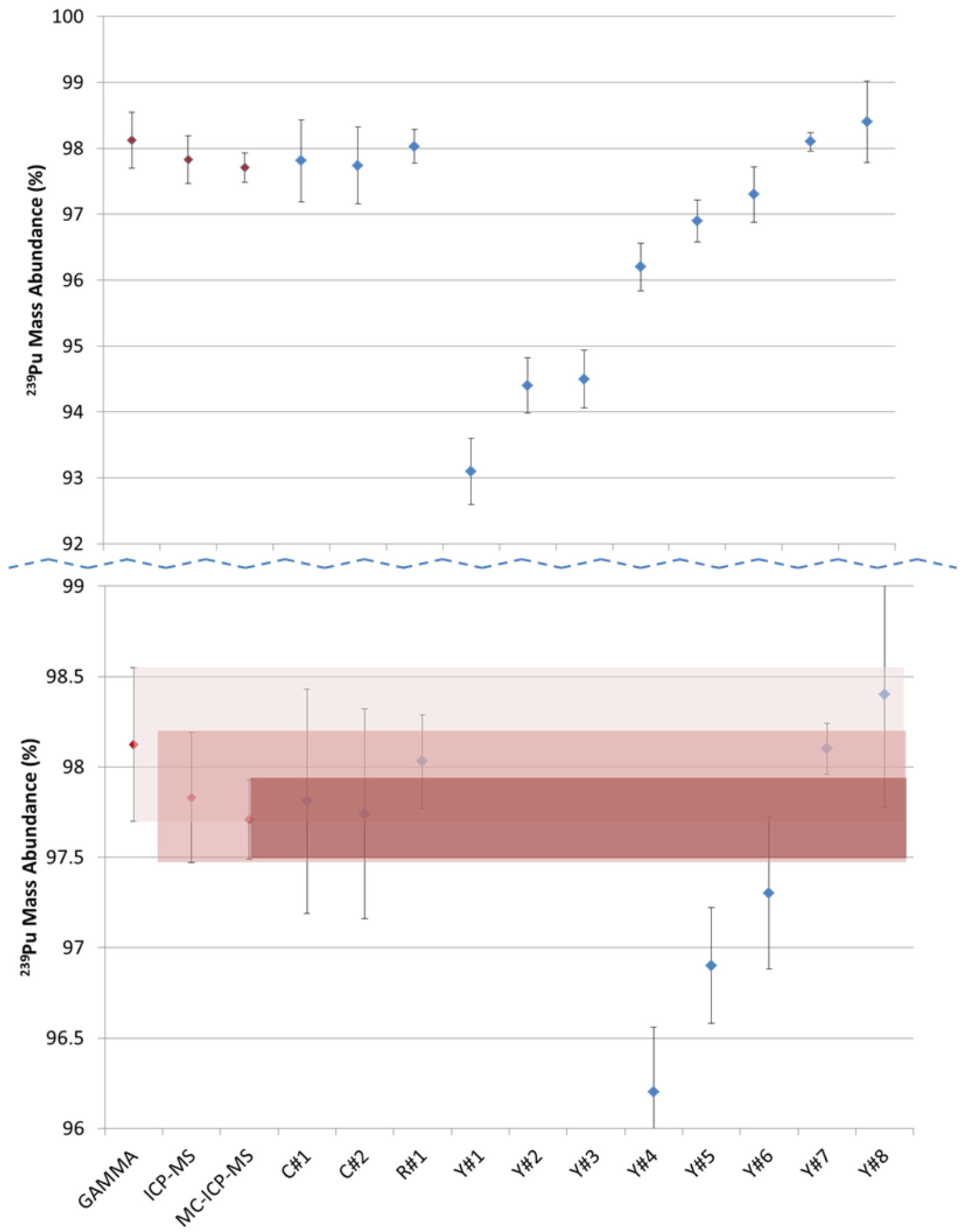

Figure I-2: Comparison of ${ }^{239} \mathrm{Pu}$ mass abundance with PuBe sources in Reimerland inventory. Light, medium, and dark red shaded area represent the $95 \%$ confidence interval around the datapoint for the unknown measured by gamma ray spectrometry, ICP-MS, and MC-ICP-MS, respectively. 


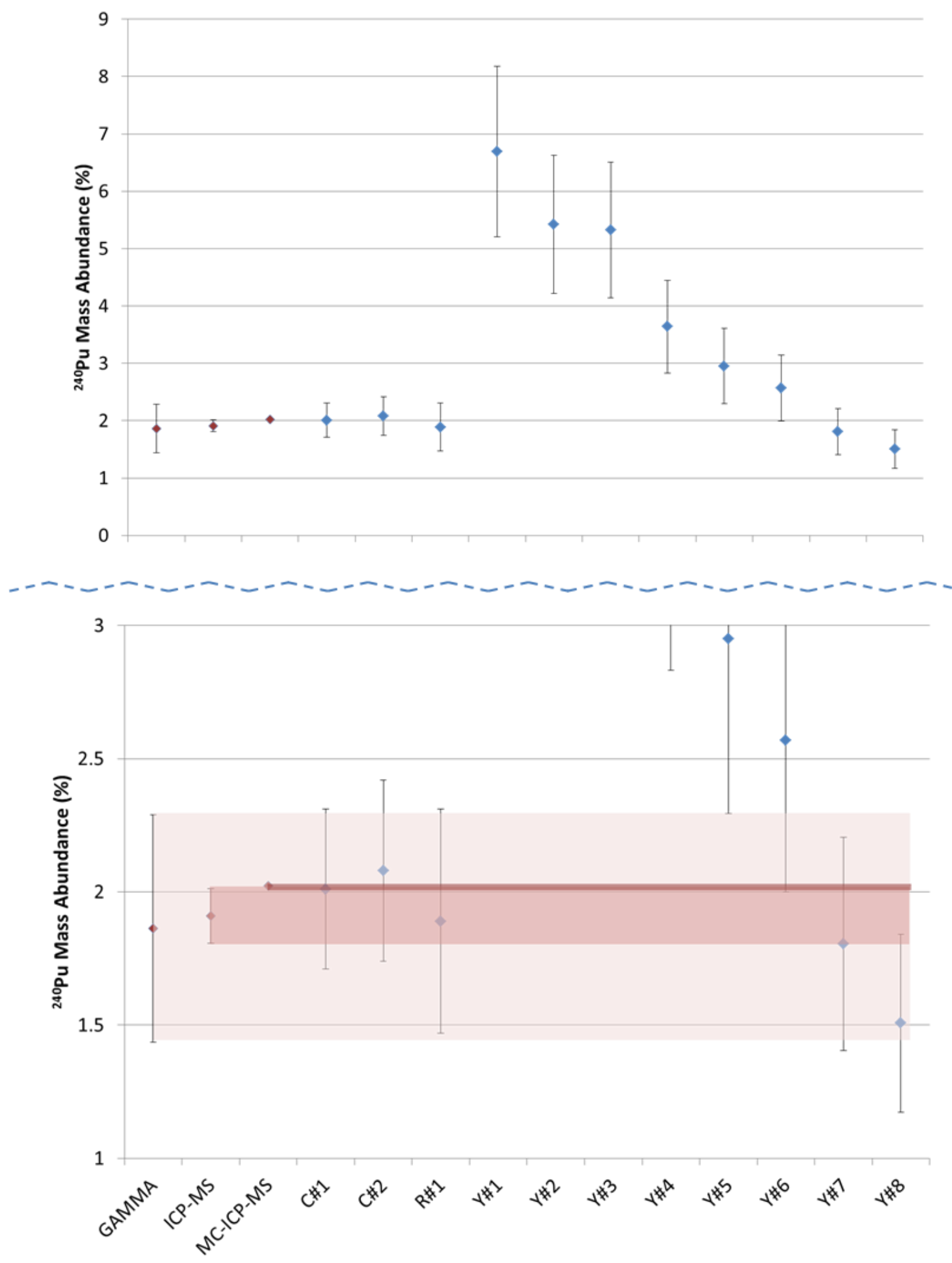

Figure I-3: Comparison of ${ }^{240} \mathrm{Pu}$ mass abundance with PuBe sources in Reimerland inventory. Light, medium, and dark red shaded area represent the $95 \%$ confidence interval around the datapoint for the unknown measured by gamma ray spectrometry, ICP-MS, and MC-ICP-MS, respectively. 


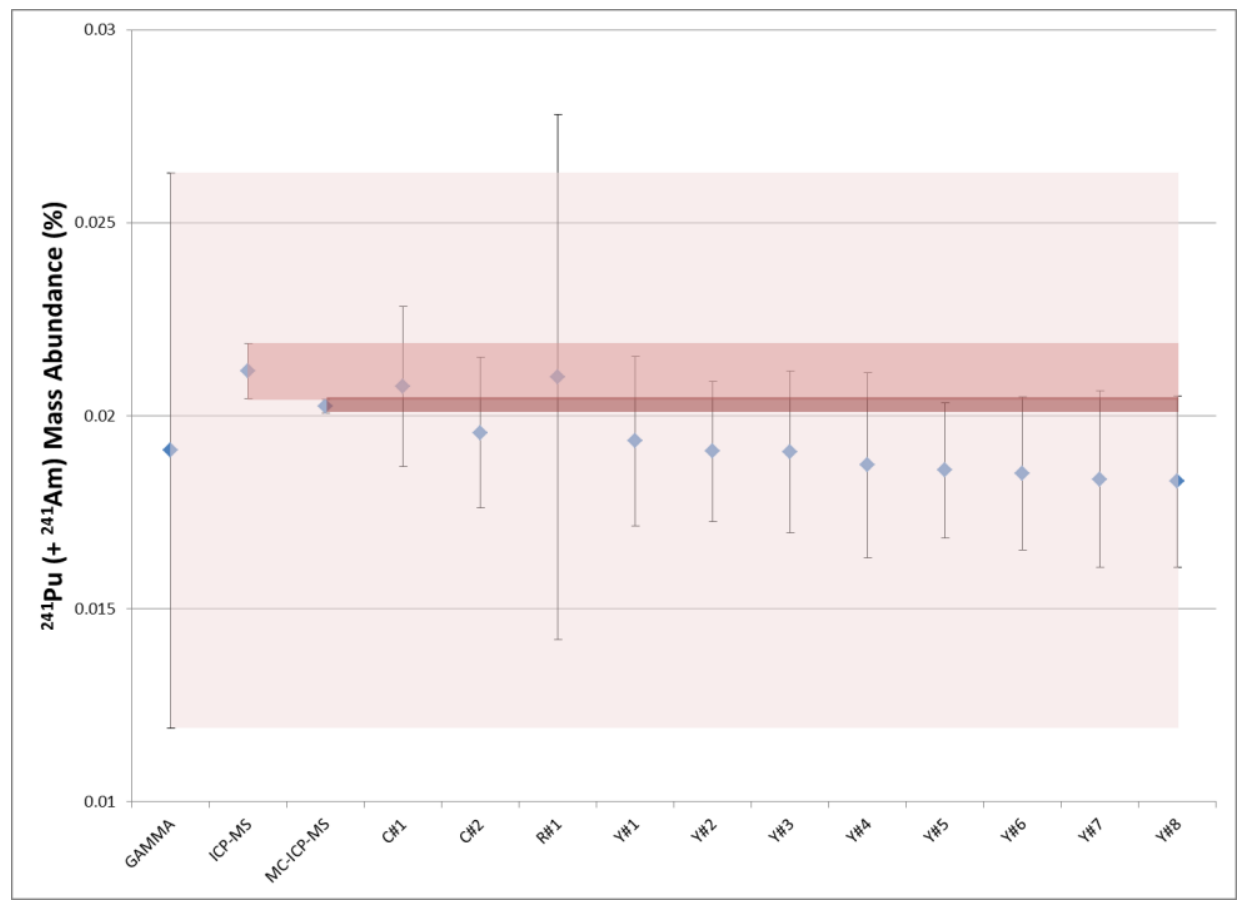

Figure I-4: Comparison of ${ }^{241} \mathrm{Pu}+{ }^{241} \mathrm{Am}$ mass abundance with PuBe sources in Reimerland inventory. Light, medium, and dark red shaded area represent the 95\% confidence interval around the datapoint for the unknown measured by gamma ray spectrometry, ICP-MS, and MC-ICP-MS, respectively.

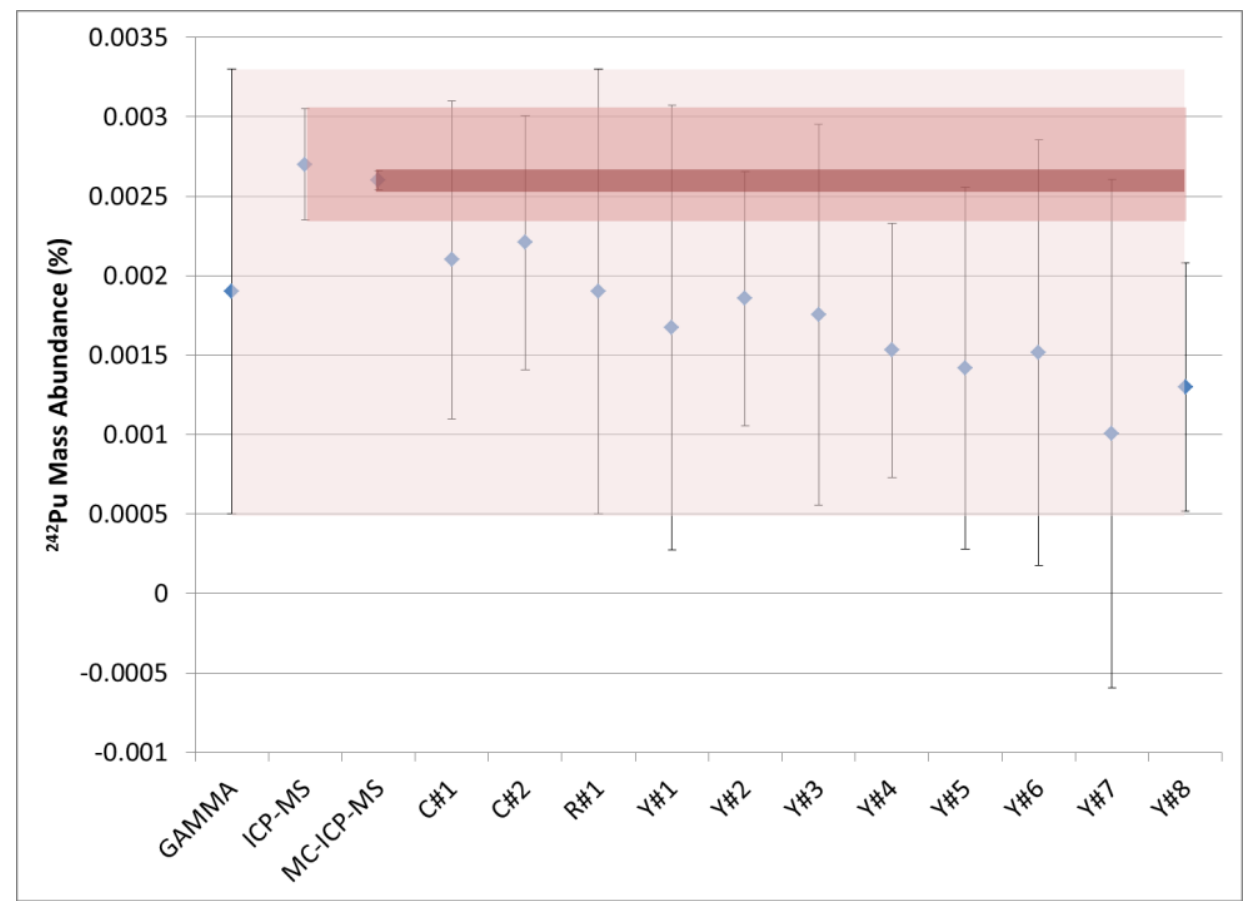

Figure I-5: Comparison of ${ }^{242} \mathrm{Pu}$ mass abundance with PuBe sources in Reimerland inventory. Light, medium, and dark red shaded area represent the $95 \%$ confidence interval around the datapoint for the unknown measured by gamma ray spectrometry, ICP-MS, and MC-ICP-MS, respectively. 


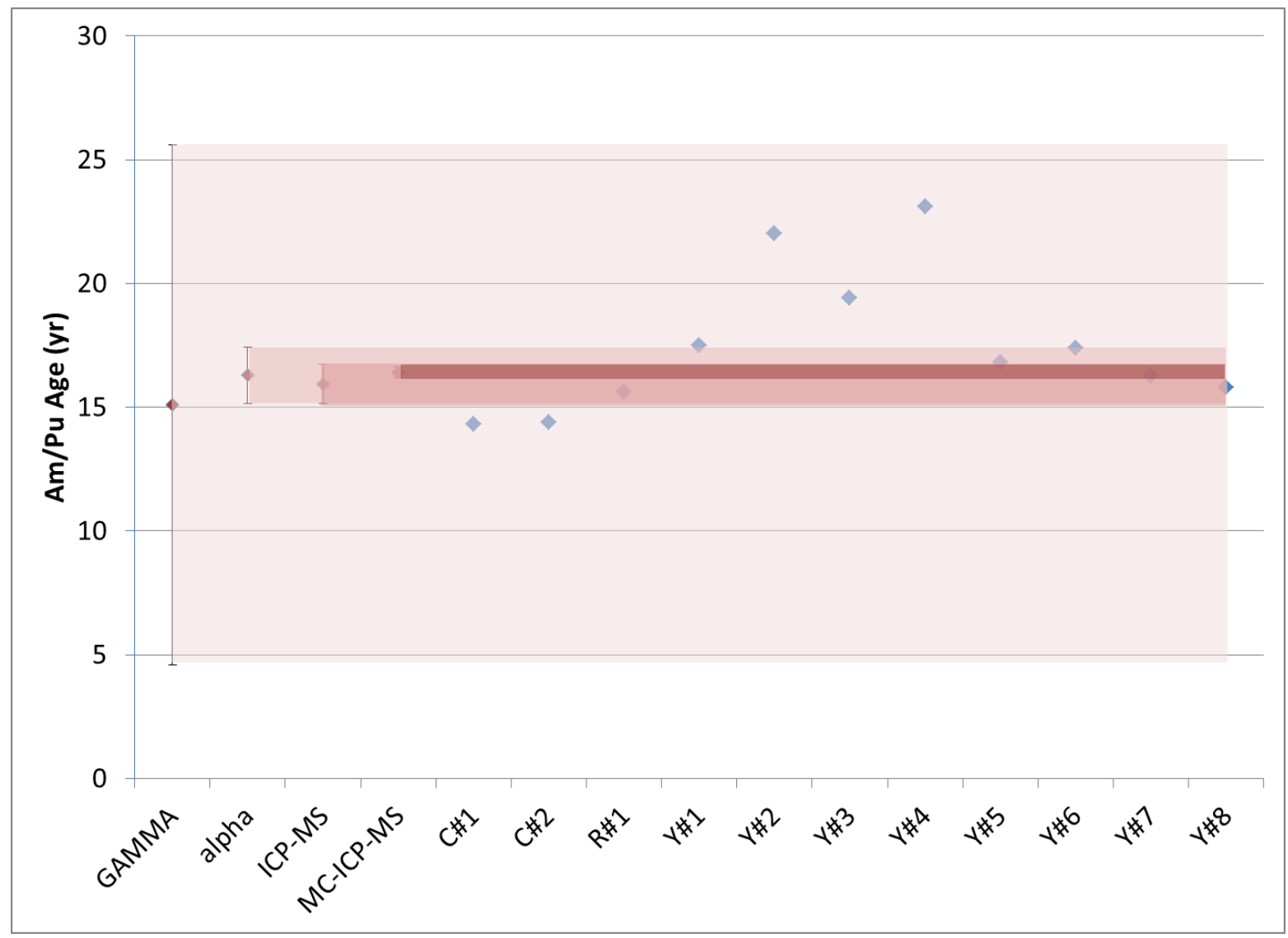

Figure I-6: Comparison of radiochronometer age based upon the ${ }^{241} \mathrm{Am} /{ }^{241} \mathrm{Pu}$ parent / daughter relationship. Light, medium, medium dark and dark red shaded area represent the $95 \%$ confidence interval around the datapoint for the unknown measured by gamma ray spectrometry, alpha spectrometry, ICP-MS, and MC-ICP-MS, respectively. 



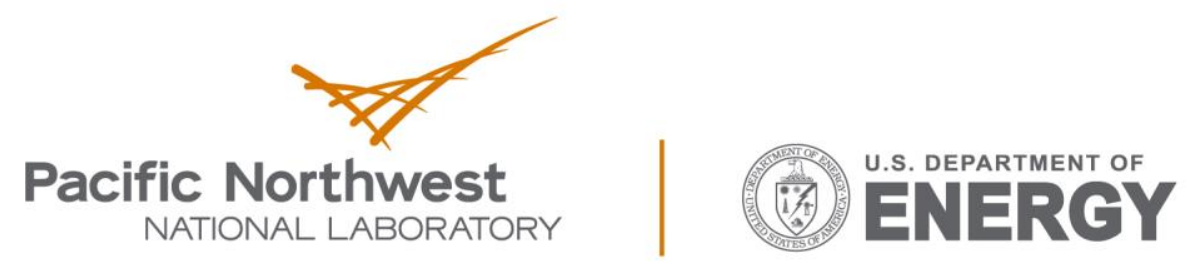

Proudly Operated by Battelle Since 1965

902 Battelle Boulevard

P.O. Box 999

Richland, WA 99352

1-888-375-PNNL (7665)

www.pnnl.gov 